\title{
PS YCHE.
}

\section{FURTHER NOTES ON SOME TINEID LARVAE.}

\author{
BY VACTOR TOUSEY CHAMBERS, COVINGTON, KY.
}

Phyllocnistis. In a former numero (v. 3 , no. 73, p. 67) I have stated that larvae of this genus molt only twice; becoming pupae at the second molt. This statement was the result of careful examinations of numerous mines and larvae, but since it was made accident has revealed what careful observation failed to discover. A short time since I observed in a mine a larva with the anterior segments so much swollen as to give the larva the appearance of a small paddle, and on removing it from the mine I found that it was in the act of molting. There are therefore three molts in this genus. This larva was only one-third grown, measuring only about $1.3 \mathrm{~mm}$. in length, whereas the mature larva measures about $3.9 \mathrm{~mm}$., but there is no intervening molt, as frequent and careful observation has shown beyond a doubt. There may be an earlier molt, but if so I have failed to find any indication of it; if there is, then according to the regular ratio which obtains in the sizes of allied genera the larva ought then to be $0.65 \mathrm{~mm}$. long.

These larvae, and those of most other leafminers, are translucent, and filled with the green parenchyma in which they are embedded, so that in their younger stages it is not only almost impossible to know whether or not they are molting, but it is difficult even to detect their presence in the leaf until they are one-third grown.

The full-grown larva, before it assumes the second form of trophi, has eight pairs of lateral pseudopodia, which are membranous, retractile and not armed with either claws or tentacles; the first two pairs, placed on the first and second abdominal segments, are smaller than the others ; there are also two long membranous retractile processes at the anal end, which seem to represent the anal prolegs of lepidopterous larvae. The pupal state continues eight days in summer, and the imago hibernates. In the last larval stage the trophi are so much aborted that it is difficult to tell what organs they represent; they are figured too distinctly, ante p. 67. The organs of the imago can be discovered within those of the pupa on the third day after the latter is disclosed and perhaps even earlier.

Nepticula. What is written above as to the difficulty of observations on young larvae of Phyllocnistis applies equally to the larvae of this genus. Until recently only one larval molt - that by which the pupa is disclosed-has been known in this genus. Another, earlier, molt has, I believe, been observed in a European species, and according to my observations (given below) the number does not seem to be the same in all the species. The larval life in the mine is too short to 
allow of more than one molt, though I find that I formerly limited it too greatly in stating that it lasted only thirty-six or forty-eight hours. It is true that in many species it does not continue longer than two or three days after the mine becomes distinctly visible to the unaided eye ; but there is an earlier period in such cases, lasting three or four days, when the mine can only be discerned by holding the leaf up to the light, and examining it with a lens, yet even then I have not succeeded in finding any other molt than that which discloses the pupa. Thus in

$N$. fuscotibiaeella Clem. I have found the larva when its length did not exceed $0.85 \mathrm{~mm}$., and the mine itself was only $1.3 \mathrm{~mm}$. long, and have watched it then for seven days more until it left the mine to pupate and yet have failed to find any indication of a molt. The mine is already about $19 \mathrm{~mm}$. long before it becomes distinctly visible; but is no wider than the body of the larva; its total length when the larva quits it is about $40 \mathrm{~mm}$. The larva is of a pale straw yellow, and when full-grown is about $3.2 \mathrm{~mm}$. The young larva is embedded in the yellowish green parenchyma and therefore is even more difficult of observation than the larva of Phyllocnistis, which lies immediately beneath the cuticle of the leaf; the space mined by it at night, when I could not observe it, shows that it had not molted at night. I detected no molt other than that which discloses the pupa. This species mines the leaves of various species of willow (Salix). It was first described by Dr. Clemens from captured specimens, and subsequently I described it also from captured specimens as $N$. ciliaefuscella, suggesting that it might be $N$. fuscotibiaeella. Afterwards I bred it from willow leaves, recognized the identity of the species, and suggested that there were two other Nepticula which also mine willow leaves, one of which, unlike all other known Nepticula, mines the under surface. The other miner of the upper surface still remains unknown, but the miner of the under surface proves to be $N$. fuscotibiaeella. The egg, like all Nepticula eggs that I have seen, is a dark brown roundish or oval microscopic speck attached to the surface of the leaf.

When it is attached to the upper surface the larva mines in the parenchyma nearest to that surface, but when it is attached to the under surface, it mines nearest to that, unless it has previously eaten through to the upper side as it frequently does early in life. In the latter part of its larval life the entire parenchyma is eaten out, so that it cannot then be said to be a miner of either surface. The egg of Lithocolletis celtisella Cham. is deposited on the under surface of leaves of Celtis, but the larva early in life eats through to the upper surface and becomes a miner of that surface. With the exception of these two species all of the mines that I have examined are under the surface to which the egg is attached, and the larva, or.imago, leaves the leaf through that surface.

I have alluded above to the fact that it feeds at night as showing that it could not then have passed a molt which escaped me, but this habit is not peculiar by any means to this species. No leafmining larva has ever been "caught napping" by me. If they ever sleep they do so either while still eating or molting or they take very short " cat naps." I have 
frequently found them when they were not feeding, but they were either molting, sick, parasitized or alarmed.

The cocoon of this species is slightly reniform, about $2 \mathrm{~mm}$. long and of a bright golden yellow. The larval life does not exceed eight days in the mine, and is therefore half as long as that of

$N$. pteliaeella, a new species of which the imago is yet unknown. Its food plant, Ptelia trifoliata, called also " Hop bush," or " Bush clover." is by no means abundant in this locality (Covington, Kentucky), at least I have but seldom met with it; but where $I$ have found it in August, every leaf is always mined by the larvae of this species, and many leaves have as many as forty larvae in each. The larva is bright green, the intestine being filled with blue-green pellets looking sometimes almost like indigo. It undergoes two molts while still in the mine, besides that in the cocoon by which the pupa is disclosed. Abundant as are the mines, $I$ have never seen the egg even on the youngest mines. It seems to become soon detached from the leaf and lost. The mine is at first an oval or irregularly roundish blotch about $2 \mathrm{~mm}$. in diameter, made by eating out the parenchyma around the spot at which the larva enters the leaf and the entire parenchyma is eaten out. About three days are consumed in making this part of the mine, but as it was already begun in each instance I cannot be more exact as to the time. The larva is now $0.8 \mathrm{~mm}$. long; it ceases to feed and undergoes its first molt. This occupies not less than fortyeight hours; I cannot be more exact because in every instance the molt was either begun or ended in the night. 'The molt accomplished, it begins to feed again, leaving its little blotch and making an exceedingly serpentine or zigzag track, packed densely with little green pellets of frass placed transversely. The mine is linear and no wider than the body of the larva; the parenchyma next to the under surface is not eaten; and if the larva happens to strike a vein in its course the mine ceases to be crooked, and passes straight along the vein. This part of the mine is very distinct from that of the first stage, is about $23 \mathrm{~mm}$. long, and it takes the larva three days to make it. Feeding then ceases, and forty-eight hours are consumed in the second molt, which being finished, feeding begins again. At the beginning of this molt the larva is $\mathbf{1 . 6}$ $\mathrm{mm}$. long, having just doubled its length since the first molt. The mine of the third stage is similar to that of the second, though readily distinguishable from it by being a little wider, and having the transverse rows of frass not so densely packed -a little wider apart-and the frass black instead of green, and in the last part of it (for $12 \mathrm{~mm}$. before the end) it is placed in a central line, and not in transverse rows. This part of the mine is so crooked that it is impossible to give its length accurately, but it is more than $75 \mathrm{~mm}$. long, and that of the whole mine is not far from $110 \mathrm{~mm}$., or twice as great as that of $N$. fuscotibiaeella. No molt occurs in this part of the mine, which is made in six days, equal to the other two stages combined, and making the larval life in the mine sixteen days - about twice that of $N$. fuscotibiaeella. The length of the larva at the end of this stage is 3.2 $\mathrm{mm}$. , just twice what it was at the second molt. (To be continued on p. 147.) 

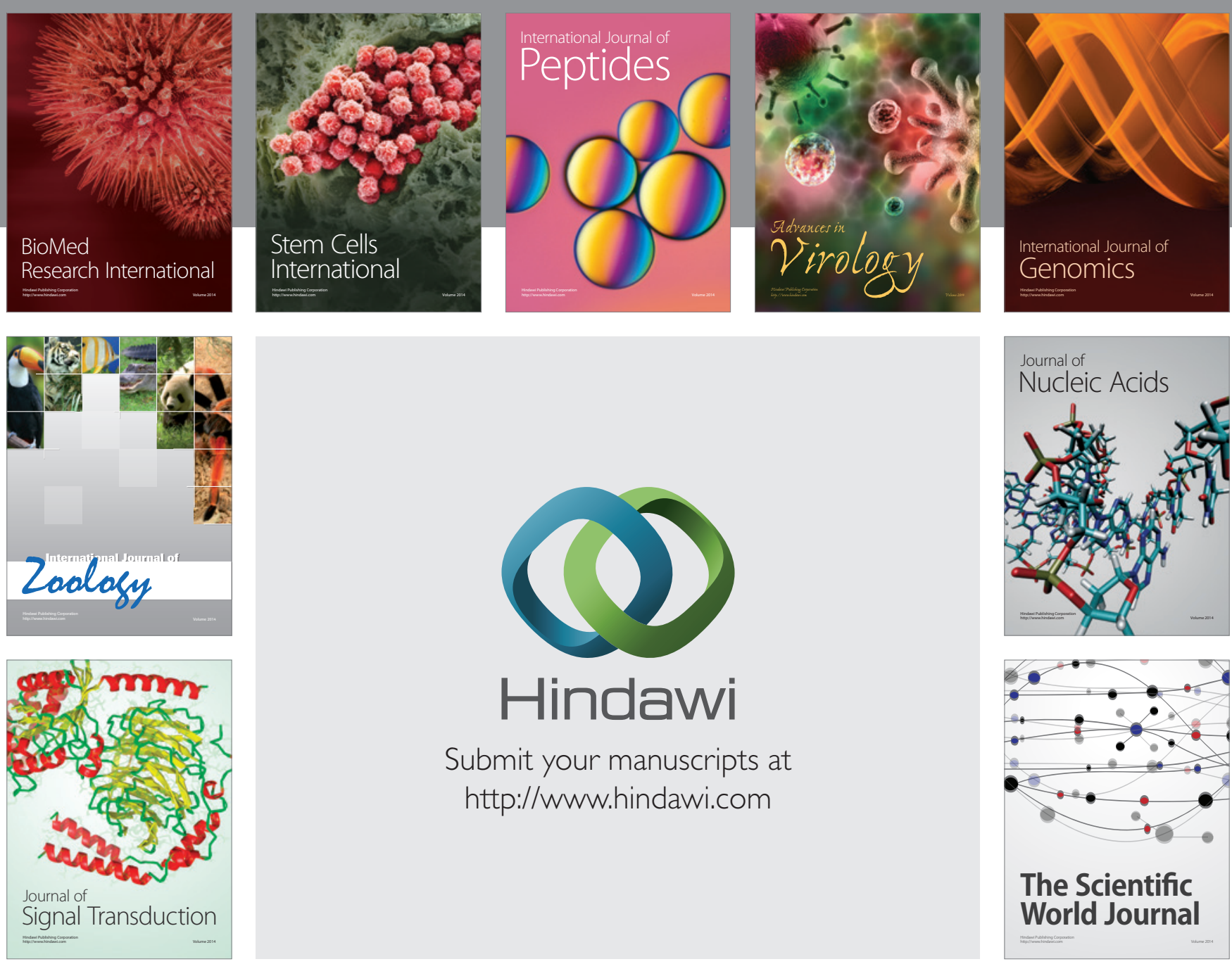

Submit your manuscripts at

http://www.hindawi.com
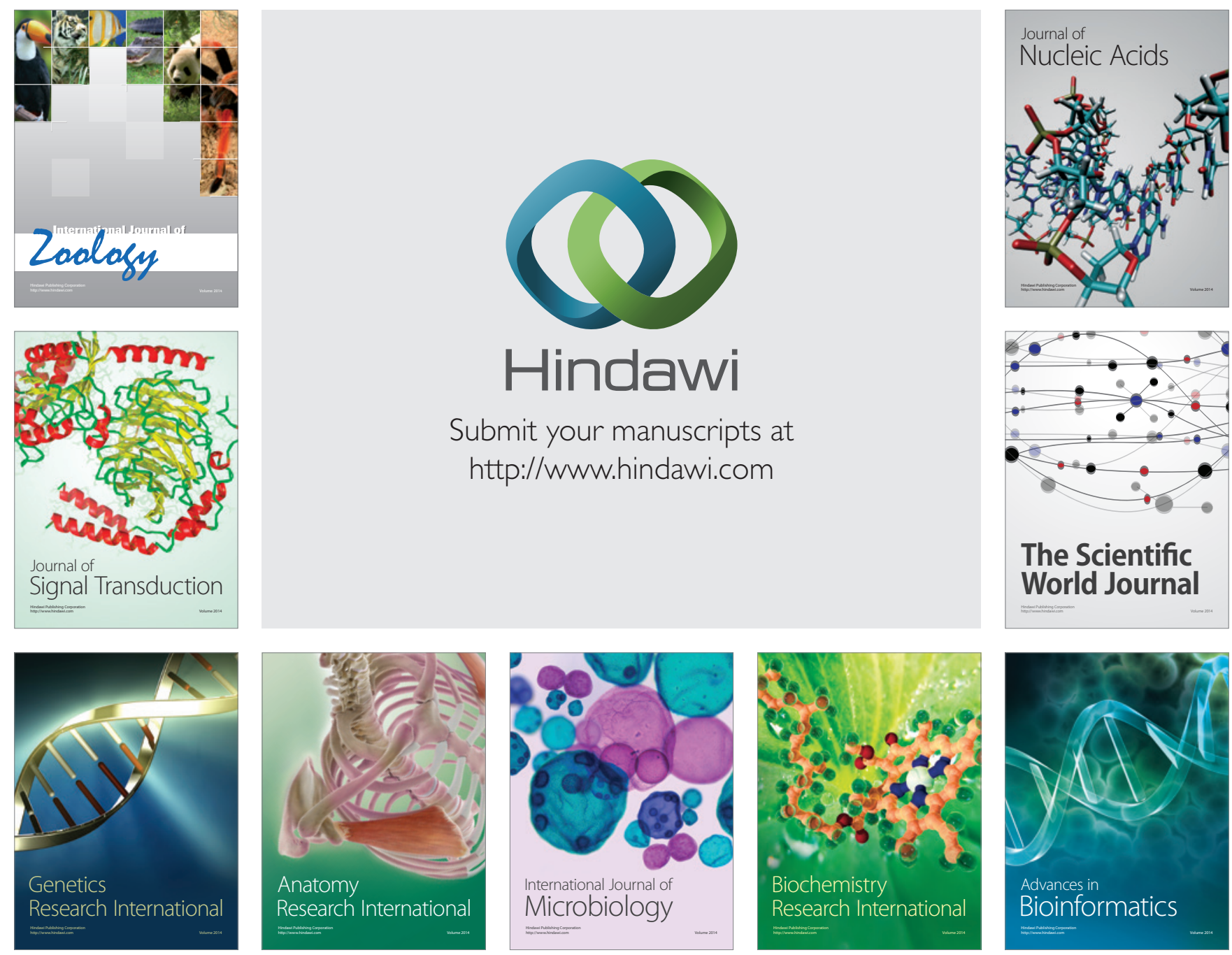

The Scientific World Journal
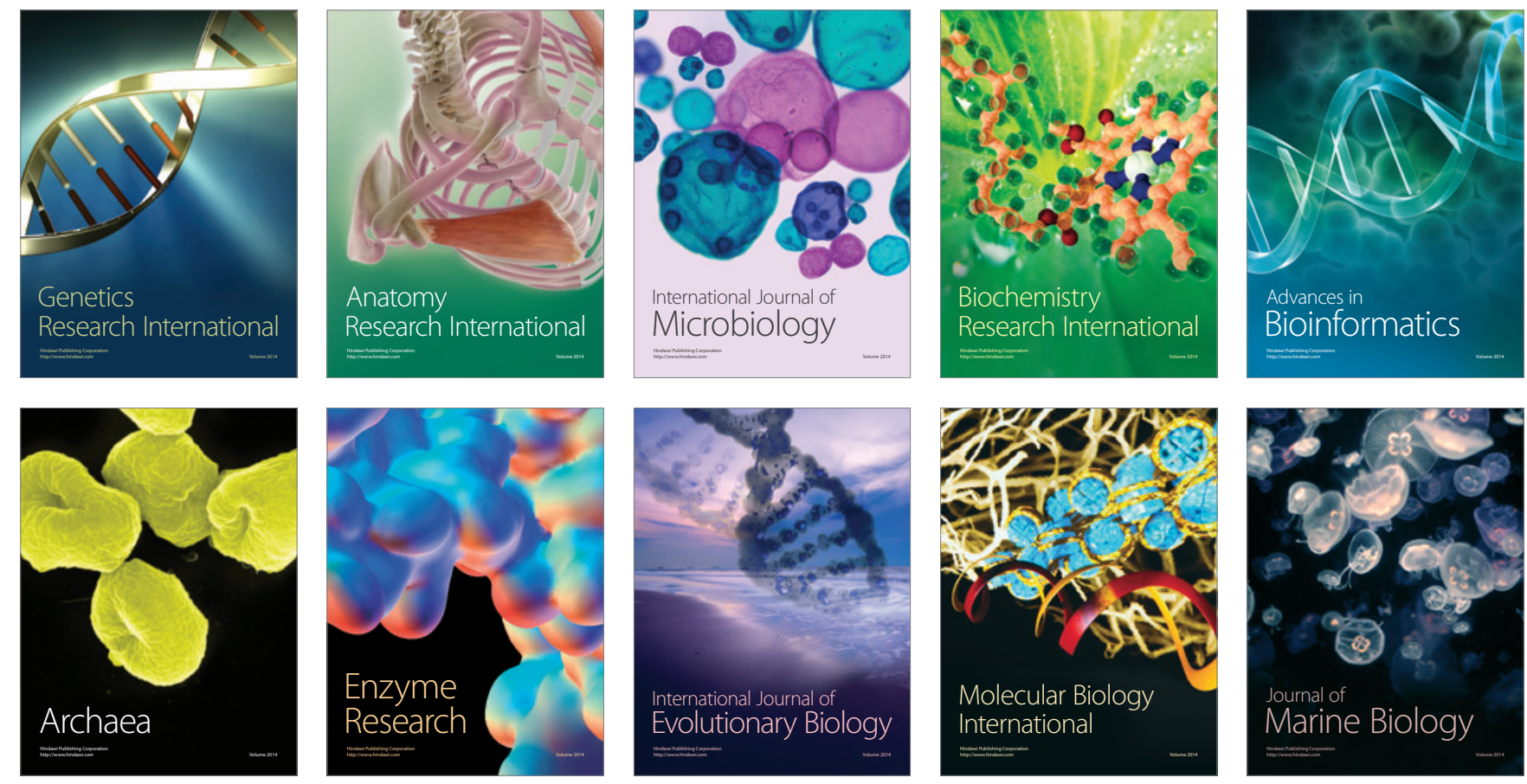